\title{
¿Qué espera un niño de un adulto? Interrogantes a partir de una experiencia lúdica grupal*
}

\section{What does a child expect from an adult? Questions that take shape in a group playful-therapeutic experience}

\author{
María Eugenia Fidalgo**
}

\section{Resumen}

Este escrito plantea el interrogante acerca de qué espera un niño de un adulto, y cómo esa pregunta toma forma en una experiencia lúdico/terapéutica grupal. Con el objetivo general de problematizar la relación niño/ adulto, partiendo de una necesaria asimetría entre ellos, se ubican algunas funciones a las que un adulto está llamado a sostener y se indaga cómo instituir legalidad, a través del análisis de cuatro viñetas de la experiencia que reflejan parte del proceso de trabajo llevado adelante con uno de los niños que participó. Se concluye que se hace necesario preservar la asimetría entre niños y adultos como condición de legalidad ineludible para que un sujeto pueda emerger desde la palabra, gestionando su propio lugar de enunciación en el lazo social.

Palabras clave: Asimetría niño-adulto, legalidad, constitución subjetiva, lazo social.

\section{Summary}

This paper raises the question of what a child expects from an adult, and how that question takes shape in a group playful/ therapeutic experience. The general objective is to problematize the relationship child/adult, starting from a necessary asymmetry between them: some functions are identified and an adult is called to support them. We investigate how to establish legality through the analysis of four vignettes regarding our experience which show part of the work process carried out with one of the children involved. We conclude that it is necessary to preserve the asymmetry between children and adults as a condition of unavoidable legality so that a subject can emerge from the language managing its own place of enunciation in the social bond.

Keywords: Child - adult Asymmetry, Legality, Subjective Constitution, Social - bond.

\footnotetext{
* El presente artículo fue escrito sobre la base del trabajo final integrador de la Carrera de especialización en Psicología clínica institucional y comunitaria (UNR) del mismo título, del que soy autora y que fue dirigido por la Dra. Silvia Lampugnani y aprobado en 2016.

** Psicóloga. Profesora en Psicología. Especialista en Psicología clínica, institucional y comunitaria. UNR
} 


\section{Introducción}

La diferencia intergeneracional constituye una condición fundante en la infancia, entendiendo a esta última como "el tiempo de la vida de los seres hablantes para encarnar la posición de bijo" (Bugacoff, 2000, p.197). Sin embargo, desde hace décadas, asistimos a diferentes modalidades de "ataque al lazo filiatorio” (Bugacoff, 2000, p.193). La autoridad, entendida en el sentido freudiano, desde ese lugar de diferencia asimétrica de aquel que ampara al pequeño en la llegada a este mundo, ha ido encontrándose con distintos modos de destitución, y la pretensión de simetría ha ido ganando terreno.

En este marco, nos preguntamos qué espera un niño de un adulto, y cómo esa pregunta toma forma en un dispositivo lúdico-terapéutico grupal con niños y niñas de entre siete y once años. Esta experiencia, que será analizada en el presente escrito, fue llevada a cabo en una escuela situada en un barrio de la ciudad de Rosario cuya población presenta un elevado nivel de pobreza y de vulneración de derechos.

En el año 2010 docentes y directivos de esa institución expresaron a profesionales del equipo de orientación de la misma un malestar vinculado a las dificultades de algunos niños en el lazo con otros, así como la imposibilidad de sostener las condiciones del espacio áulico. Los niños recorrían con sus cuerpos cada rincón en busca de algún borde que operase como límite. Como respuesta a esa demanda, miembros de dicho equipo, en articulación con la facultad de Psicología (a través de la carrera de especialización en Psicología clínica, institucional y comunitaria), elaboraron la propuesta de un dispositivo grupal en el que, a través del jugar
(Winnicott, 2008), entendido como "práctica significante" (Rodulfo, 2001, p.120) fundamental en la estructuración subjetiva de un niño, se pudiese abordar esta problemática. La propuesta, planteada como invitación al niño y a su referente familiar, en general la madre, permitió diferenciarse de la obligatoriedad con que se asocia habitualmente a la escuela.

El proceso que fue haciendo uno de los niños que participó, a quien se nombrará como Manuel, oficiará de hilo conductor en este escrito que presentará el análisis cualitativo de viñetas de esa experiencia.

A lo largo del presente trabajo se buscará problematizar la relación niño - adulto. Para esto se caracterizarán algunas de las funciones que un adulto está llamado a sostener, se indagará respecto de los modos de instituir legalidad, y se analizará aquello que es posible leer como ausencia de apelación a un adulto y los intentos por constituir esa función, instalando también la posibilidad de volver a tejer el lazo con los pares.

Los nombres de los niños, las referencias históricas y los fragmentos de las escenas reconstruidas en el presente trabajo, fueron modificados atendiendo al resguardo de la identidad de quienes participaron de esta experiencia.

\section{Algunas consideraciones acerca de Manuel}

Manuel comenzó el espacio de juego con ocho años y participó durante dos (2010 y 2011). El pedido de las docentes de que se incluyera tuvo que ver fundamentalmente con la violencia (así aparecía enunciado) para con sus compañeros y con su 
dificultad para sostener el espacio del aula. Manuel no se encontraba alfabetizado. Sufrió en una edad muy temprana una lesión en su cuerpo, una pérdida traumática que no encontraba en el discurso familiar una vía de tramitación posible, pero quizás lo que había dejado marcas aún más difíciles de tramitar era el haber recorrido estos años en medio de un discurso familiar signado por el rechazo y la imposibilidad de libidinización que produjera para él algún tipo de alojamiento subjetivo.

Teniendo en cuenta que el deseo del adulto posibilita generar o desplegar el deseo del niño y también una vía para crear una base de seguridad y confianza en sí mismo, podemos decir que este espacio de juego se convirtió en algo muy valioso para él, para hacerse un lugar, distinto de aquel centrado en lo que Manuel no podía o no hacía, afirmación que le resonaba en numerosas oportunidades. La dirección del trabajo con este niño en el transcurso de los encuentros del taller tuvo que ver, en gran parte, con instaurar la posibilidad de constituir una reserva libidinal frente al Otro, un Otro en el cual quedaba entrampado la mayor parte del tiempo y que le imponía obstáculos para constituirse como sujeto deseante.

Fue en los modos de hacer lazo del niño con sus pares, en la experiencia con esos otros, donde los coordinadores, en tanto adultos, se encontraron, a través de las intervenciones, intentando devolverle al niño el recurso de apelación a un adulto, en muchas ocasiones como mediación o como terceridad frente a lo que de sus pares le retornaba como amenazante. El jugar, en ese marco, apareció como una apuesta que se renovaba cada vez como un recurso privilegiado.

\section{Sobre las viñetas}

Los registros que aparecen en este escrito guardan una secuencia cronológica, que de algún modo invitan al lector a acompañar parte del recorrido que este niño fue haciendo en el espacio. No obstante, este ordenamiento de ningún modo alude al tiempo que se puso en juego en el trabajo; esto es, los tiempos lógicos, no cronológicos, de un proceso de subjetivación en medio de un trabajo clínico. Los efectos del trayecto de Manuel por este taller son pasibles de ser leídos en el aprés coup, lo que implica avances y retornos en el relato de la experiencia.

Las cuatro viñetas elegidas y sus líneas de análisis permiten ir pesquisando el proceso de subjetivación que Manuel fue haciendo en esta experiencia grupal, proceso en el cual fue fabricando con estos pares y adultos un lugar que lo alojase en el discurso. Así, fuimos ubicando en este material los modos en que la pregunta por lo que se espera de un adulto en relación con un niño intentó ir tomando forma y qué posibilitó lo grupal como marco.

\section{1- Sujetos que cuentan}

Sentados alrededor de una mesa, los niños van contando cuántos son en ese encuentro, quiénes están presentes, quiénes ausentes. Uno de los niños cuenta que a Manuel le pegaron antes de venir porque le sacudía la cama a la madre que estaba durmiendo. El resto sigue hablando de otra cosa.

Alguien propone escribir los nombres de quienes están allí. Manuel dice que él no va a escribir su nombre. El coordinador le 
propone escribirlo en un papel y que él lo copie. Acepta y lo escribe. Como no podía escribir su edad, ocho, el coordinador se lo muestra, pero no lo escribe. Fernando, otro de los niños, le muestra cómo: dibuja dos circulitos, uno arriba del otro y finalmente Manuel puede escribirlo así.

Hablando de situaciones que les hacen sentir vergüenza, uno de los niños se ríe de Manuel y se burla de que "se hace pis encima", también de que no sabe escribir. Manuel baja la cabeza y no responde. La coordinadora interrumpe diciendo: "Les propongo un acuerdo: decir lo que a cada uno le da vergüenza pero no decir cosas del otro".

\section{......}

Contarse en ese espacio crea una pertenencia que sostiene el lazo colectivo. Es un modo de ubicar que no da lo mismo estar presente o ausente en cada encuentro. Si alguno no asiste, va a faltar en la cuenta que el resto hace. Pero contarse entre otros, contar con otro y contar a otro es también narrarse, historizarse al interior de este espacio de juego.

Este pequeño acto se constituye por esto en un acto subjetivante, "ceremonia mínima" (Minnicelli, 2013, p.43), que introduce una legalidad en el intercambio. Esta categoría conceptual alude a la puesta en valor de aquellos pequeños actos cotidianos que pasan desapercibidos en el devenir de la práctica, pero que sin embargo constituyen instancias de intervención que dan lugar a otras redes discursivas, implicando, por esto, "un reposicionamiento subjetivo de los adultos ante los niños, niñas y adolescentes" (p.55), razón por la cual se hace necesario recuperar el valor que los mismas poseen.

De ese modo va tomando cada vez más importancia para Manuel y para los demás niños, ser esperados y recibidos en el espacio, otorgar valor al encuentro, a la presencia de cada uno y conversar acerca de cómo se sienten, instituyendo en ese mismo acto una legalidad en la que se van situando los sujetos en su enunciación.

La intervención en la cual se pide a todos "hablar en nombre propio y no contar cosas del otro" produce una interrupción, introduce un corte sincrónico en el devenir del encuentro, para señalar este orden de legalidad: los sujetos en la enunciación no son intercambiables. Cabe la pregunta aquí acerca de cómo pensar ese orden de legalidad que intenta enmarcar el intercambio.

¿A qué nos referimos cuando hablamos de instituir legalidad? Para Minnicelli (2010) institución designa "la marca simbólica de la diferencia que inscribe al hablante en la legalidad del lenguaje" (p.59). Y que por esto: "implica establecer un corte sincrónico en una continuidad diacrónica” (2008, p.5). La institución, entonces, es marca simbólica de la diferencia

En el encuentro, a través de ceremonias mínimas, se va realizando ese corte sincrónico, se van inscribiendo otros decires, otros significantes, teniendo presente que el dicho tiene carácter de acto. Se va interrumpiendo con lo que siempre fue así, de esa manera, y por ende con el carácter de lo destinal. Esto también supone investir al niño en el campo del Otro, hacerlo pasar por el deseo del Otro, donde el sujeto puede inscribir algo del orden de su significación.

La legalidad, que es la legalidad del inconsciente, forma parte del encuadre, que 
se va estableciendo en el trabajo, grupal, en este caso. En tanto ley paterna, se introduce a través de enunciados de este tipo, con una característica fundamental: la ley rige para todos, tanto para los niños como para los adultos, aquí en su función de coordinadores, $y$, por ende, introduce un ordenamiento. La misma ofrece, en tanto legalidad de lenguaje, un marco simbólico como punto de partida para el intercambio. Esto es, como destaca Bleichmar (2010), lo que diferencia la ley del padre de la ley perversa o la arbitrariedad del poder, e incluso podríamos decir, del mero disciplinamiento o la reeducación.

En el espacio se les propone una alternancia, cada uno tiene su turno para hablar y de la propia intimidad sólo cada uno puede decir, es sólo en nombre propio que algo de esto puede ser enunciado. Aparece una demanda no articulada aún, dirigida al adulto, para que regule con la palabra el lugar de cada quien y mediatice la imagen del otro.

Freud (1997a) plantea que en la vida anímica "el otro" aparece siempre integrado ya sea como modelo, como objeto, auxiliar o adversario. Como señala Minnicelli (2013), desde edades muy tempranas los chicos advierten y ponen de relieve las más mínimas diferencias. Nuestro lugar allí, en tanto adultos, tiene que ver precisamente con reconocer con ellos la diferencia pero no en tanto aquello que estigmatiza y contamina el lazo social, sino en la medida que es aquello que marca las singularidades entre los semejantes, haciendo único a cada sujeto.

\section{2- Movimientos para el recorte de una mirada}

Solo Manuel y otro niño asisten a este encuentro. Ambos quieren jugar a las cartas. Los coordinadores se suman. Manuel, inquieto, se sienta, se para, da vuelta la silla, no espera su turno, cuestión que se le señala en cada jugada de otro compañero, ya que él empieza a hacer la suya cada vez que otro termina, sin registrar el turno. Los coordinadores proponen, en primer lugar, acordar y escribir cuáles son las reglas. Uno de los niños agrega como regla final: "No se pueden espiar las cartas". Manuel deja ver todo el tiempo las suyas, ante lo cual la coordinadora advierte: "Cuidado, Manuel, que te las vemos, tapalas". Abre con mucha ansiedad los cajones de la mesa sobre la que jugamos, mira lo que hay dentro, saca unos papeles y el coordinador le dice: "Eso no se abre ni se mira, hay cosas que no se pueden ver, que no son nuestras", y le cierra los cajones. Manuel sigue dejando ver sus cartas, a pesar de que se le vuelve a decir que no las muestre; el coordinador se tapa los ojos y dice: "No, no quiero mirar, porque Manuel muestra las cartas y yo no las quiero ver". Todos se tapan los ojos, incluso el otro niño. Luego cuando vuelven a mirar, Manuel se ríe y empieza a jugar a que le muestra las cartas al coordinador, él se vuelve a tapar los ojos y a decir que no quiere ver. Manuel y el otro niño se divierten. En otro momento, con sus cartas a la vista, le dice a la coordinadora que se encontraba a su lado: "Me estás espiando, tramposa". Ella le responde que no las ha visto.

Los movimientos entre dejar ver, ser visto, mostrar, tapary ser espiado van inscribiendo di- 
ferencias en la posición del sujeto con relación al Otro. Tener "todo a la vista" (que no es lo mismo que mostrar) ubica a Manuel en tanto puro objeto, a merced del Otro, sin poder contar con la posibilidad de una reserva, que lo preserve de ese avance sobre el cuerpo, forzosamente desubjetivante. Es durante la propuesta lúdica que Manuel puede empezar a instalar el jugar a mostrar, como si pudiera comenzar a decir: "No soy yo quien dejo ver, sino que sos vos que me espiás, y de que me intento tapar, me puedo cubrir". ¿Cubrirse de qué? De ser visto, que no es lo mismo que ser mirado. La visión, en tanto acto perceptivo, se diferencia de la mirada, en tanto acto efectuado por el yo, y que implica una determinada posición subjetiva de quien mira, respecto de su semejante.

Este movimiento se posibilita a partir del discurso que habilita el lazo social ya que lo que se introduce, aunque no aparezca enunciado en estos términos, es: "Si vos no tapás tus cartas no podemos jugar así, queremos que juegues con las mismas reglas que el resto". Alguien puede jugar una vez que puede construir una reserva libidinal. Son estos tipos de no los que, como dice Miniccelli (2004), transportan e inscriben la norma.

Con las reglas de juego inventadas y escritas colectivamente, lo que se hace es, ni más ni menos, que escribir la ley, decir: "No todo es posible", a todos se nos prohíbe hacer determinadas cosas y a todos se nos habilita a hacer otras. Nadie queda por fuera.

Una de las reglas explicitadas por los niños antes de iniciar este juego fue: "Al que le toca, le toca", afirmación que no impide ubicar una apuesta: ¿qué hace cada uno con lo que le toca? Y esto tiene que ver con la posibilidad que un sujeto tiene de establecer una diferencia con aquello que amenaza desde el carácter de lo destinal. El destino, en tanto pasado que es vivido como futuro ineludible, no abre a la posibilidad de ningún tipo de movimiento que el sujeto efectivamente puede hacer y, mucho más, cuando hay otros que lo habilitan a ello. Perpetuarse como sujeto de excepción, como Freud (1997b) lo describió, sume al mismo en la imposibilidad de escribir e inscribir otras marcas posibles, distintas en su historia. Freud se ha referido así a aquellos sujetos que asumirían en la vida una posición subjetiva que los exceptúa de las restricciones y exigencias que atraviesan a todo ser humano, por el hecho de haber sufrido lo suficiente en la vida, especialmente en los primeros años infantiles, excepción que vendría a ocupar cierto lugar de compensación por semejante infortunio.

Muchas veces, el trabajo en contextos de pobreza conlleva el riesgo de que seamos los que trabajamos con los niños los que los ubiquemos en esa posición de excepción. En este sentido, es importante situar que cuando esto cede y puede dirigirse otra mirada que no los coloque como excepción, esto es, por fuera del atravesamiento de la castración, se abre otra vía posible de trabajo con efectos claramente subjetivantes para ellos.

En este encuentro es Manuel quien enuncia el engaño, la trampa, como movimiento que posibilita agujerear al Otro, suponerle una falta. Se puede hacerle trampa al Otro cuando no se está en la trampa del Otro, cuando no se está entrampado allí. Esta falta tiene que ver con la dimensión del saber: el Otro no puede saberlo todo, que 
no es otra cosa que reconocerlo atravesado por la castración.

Se intenta habilitar a Manuel a que pueda ahuecar esos significantes maternos que se le presentifican con un tenor imperativo, convirtiéndolos en significantes en falta de significación y jugar con ellos.

\section{3- "Si no estarían ustedes dos..." Apelación a un adulto}

Manuel le cuenta a Lucas, un niño nuevo en el taller, que la vez anterior jugamos a los karatekas, a lo cual Lucas le responde: "Yo pego patadas". Manuel enseguida le aclara que eran "demostraciones", que no se pegaban. Por momentos, se agreden con palabras y Lucas mira a los coordinadores y advierte: "Si no estuvieran ustedes dos ya nos habríamos agarrado a las piñas".

Lucas pregunta si hay otros juegos ahí, Manuel le dice: "Sí, un montón de juegos". Se lo ve a Manuel hablar de un espacio del que se ha apropiado, hace comentarios acerca de lo que sabe. Lucas pregunta por el tiempo que Manuel lleva en el espacio. "Hace mucho que vengo", responde y pide al coordinador que le precise desde qué día comenzó a participar. Le responde: "Desde el 6 de enero." Manuel agrega que ese día es su cumpleaños.

Ya finalizando el taller, mientras guardan los materiales, Manuel comienza a hacer demostraciones de karatecas, mientras Lucas le habla a la coordinadora. En ese instante empieza a quejarse y a decir cosas, enojado. Cuando le pregunta qué le pasa, responde: "Es que no me mirás...".

¿No hay acaso aquí una apelación clara y directa al adulto, como aquel que ejerce su lugar de diferencia, asimétrica, respecto de los niños? Es desde la misma palabra de este niño que la mirada se vuelve hacia los adultos. Como tales, somos llamados, en tanto capaces de interferir, de mediar, de interrumpir si es necesario, cuando la relación especular imaginaria se vuelve intolerable y se hace necesaria la mediatización simbólica. Por otro lado, es necesario reestablecer esta posición en la trama social, donde desde hace décadas, como advierte Minnicelli (2013), se ha generalizado una posición de espectador que deja a los más chicos librados a las formas pasionales, y muchas veces violentas, de zanjar las diferencias y lo que no se tolera del otro.

La indiferenciación de lugares produce forzosamente, en muchos casos, modos desubjetivantes de habitar el lazo con el otro, marcados por la imposibilidad, a merced de lo que suceda sin poder hacer casi nada al respecto, como advierten Duschatzky y Corea (2009). Estas autoras postulan que "en ese marco de disolución y confusión, la desubjetivación consiste en la imposibilidad de gestionar lugares de enunciación” (p.73), a partir de lugares estables de referencia.

Algo opera en el marco simbólico del taller, en la posición subjetiva de los adultos que allí sostienen el espacio (y sostienen a los chicos), que logra, aunque no siempre, legislar el lazo con el otro para que los conflictos y diferencias entre pares encuentren otras vías posibles de resolución.

La diferencia intergeneracional que instala la asimetría entre el niño y el adulto, conlleva una legalidad absolutamente necesaria. El niño necesita oponerse e iden- 
tificarse, necesita que se le prohíba y, en el mismo acto, se le habilite a otra cosa.

Es importante señalar que en el adulto siempre está presente algo del niño que fue (Frigerio, 2008), "el núcleo vivo de lo infantil" (p.74) perdura en él de manera inconsciente, por lo que esos trozos de infancia siguen teniendo actualidad e imprimen, "entre bambalinas" (p.74), la relación con los niños que ese adulto tenga.

Ahora bien, una cuestión es reconocer lo infantil del sujeto adulto que se pone en juego en la relación asimétrica con el niño y otra muy distinta es homogeneizar los lugares, borrando esa hiancia que el infantil sujeto necesita para crecer. Esa diferencia niño-adulto se hace totalmente necesaria para garantizar de algún modo esa institución de infancia, de la que habla Minnicelli (2010), establecer la diferencia apelando "al Tercero social de la palabra como instancia simbólico-social que oficie en su función de límite, de separación, de restitución de la ley" (p. 236).

Pero no sólo el niño reside en el adulto. El niño va fabricando también su propia representación del adulto, que si bien tendrá que ver con los elementos que le aporten los grandes, cercanos a su crianza, una cuota considerable tendrá que ver con lo que él mismo puede crear. Al respecto Frigerio (2008) señala:

El adulto en el niño reside como representación del otro. Representación de la cual la ambivalencia nunca está ausente. Devenido interlocutor interno de un mundo externo, el adulto puede ejercer tanto la tiranía de un superyó imposible de satisfa- cer como dejar vacante un lugar: esa vacancia vuelve dificultoso el crecer. (p. 82. Las cursivas son nuestras)

Se entiende que esto no significa que esa tiranía superyoica no lo dificulte (de hecho lo hace, y mucho), pero, al menos, el niño puede hacer algo con ella, y lo que pueda hacer producirá distintos efectos subjetivos. No obstante, ¿qué sucede cuando en cambio, del otro lado no hay nada, y el adulto está ausente en tanto tal para habilitar el campo de juegos identificatorios para la construcción de la propia identidad? ¿Puede filiarse un niño sin un adulto que le ofrezca condiciones para esa operación?

Según Kreszes (2000) la filiación es un proceso de nominación que se plantea en dos direcciones: del padre hacia el hijo y del hijo hacia el padre, y que el Otro no basta para ello, sino que quien se filia también lleva adelante un proceso de apropiación necesario para que esa operación tenga lugar. Entonces, estaremos de acuerdo en decir que tampoco el niño solo basta, sino que para filiarse necesita de quien, encarnando al Otro ya sujeto del lenguaje, lo nomine, lo nombre, y lo inscriba en la cultura, sancionando un lugar y transmitiendo la ley. ¿Cómo prescindir, entonces, de esos adultos, de aquellos que participamos de la vida de los niños y niñas desde diferentes lugares, si deseamos que puedan hacer lazo social con sus pares en condiciones que les permitan constituirse como sujetos de la palabra?

Esa pertenencia que Manuel manifiesta con relación al espacio tiene que ver con este contarse dentro del mismo. Él puede narrar su historia allí y puede narrar a otros 
qué cosas son posibles, qué cosas pueden hacerse y con qué cuentan. En definitiva, de lo que habla es de un lugar con un marco de legalidad que permite el lazo social.

Nacer no es sólo venir al mundo, y Manuel lo demuestra enunciando que el día que comenzó a venir al taller es el día en que cumple años. Él sabe que objetivamente esto no es así, pero sabemos que la realidad psíquica que se entrama en el deseo difiere del dato de la realidad material. Esta cuestión sólo puede ser sentida en el après coup, luego de haber hecho este proceso y ubicarse en un circuito de deseo. Es un sujeto que se sabe alojado en el discurso, y esto es lo que lo hace niño. Es un sujeto de deseo, del cual se espera algo y, en consecuencia, se crea el espacio para que pueda producirlo en la experiencia compartida.

\section{4- ¿De qué se pierde Manuel?}

Manuel llega varios minutos luego del inicio del taller, quejándose de que su mamá lo trae tarde. Como en algunas ocasiones previas, la madre pide hablar con el coordinador. Esta vez, él le dice que ya ha comenzado el encuentro, que conversarán en otro momento, teniendo en cuenta el malestar que Manuel había manifestado otras veces. Esta escena es repetida por ella: lo trae tarde y le pide al coordinador hablar con él a solas. "Siempre hace lo mismo", se queja Manuel, sintiendo que su madre invade un espacio y un tiempo que es para él.

Manuel construye una casa con maderitas. Llama a la coordinadora para que la vea, quien le dice que está hermosa y le pregunta quién vive allí; "Vos", le responde. Luego hace una torre, vuelve a llamar a los coordi- nadores para que miren lo que hizo: "Mirá lo que bice... yo solo".

Uno de los chicos lo interpela: "¿Por qué te molesta llegar tarde?". Una de las niñas dirige su mirada a Manuel y, casi completando el interrogante de su par, e intentando acercar una respuesta posible, pregunta: "¿Porque te perdés de jugar?”

......

Manuel puede enojarse ante la intrusión del Otro, se separa de su madre quejándose de que lo lleve tarde y de su insistencia en apartar al coordinador para hablar con él. Cuando Manuel pide puntualidad a su madre para llegar a horario al taller, no hace otra cosa que demandar legalidad, revelarse a un claro ataque al encuadre del espacio. El enojo de Manuel tiene que ver con esto, ante el avance del Otro, él pierde y se pierde (“te perdés", le dice esta niña), pero a diferencia de otras veces, puede ligar su angustia a lo que representa esta irrupción de la madre en un espacio que es para él y enojarse.

Como enfatiza Amigo (2005), el trabajo analítico es un trabajo no sólo de corte, sino también, y muchas veces fundamentalmente, de empalme, en el sentido borromeico del término. Se trata de constituir una consistencia imaginaria que envuelva, que rodee, que unifique ese cuerpo; un cuerpo que puede ser mirado desde Otro que lo inviste libidinalmente, que le otorga ese brillo fálico y lo ubica, así, en un circuito de deseo. La mirada del Otro estructura lo imaginario, hace consistir al cuerpo. Lo interesante es que es Manuel quien, luego de este tiempo de trabajo, demanda esa mirada y, al mismo tiempo, puede quejarse de quien, por momentos, lejos de 
donarle un lugar subjetivante, lo desarma y lo injuria. Sus dichos - “ ¡Es que no me mirás...!" "Mirá lo que hice, yo solo"- son una demanda de falización, demanda en transferencia. Busca en el espejo el reflejo que el otro puede devolverle: una imagen unificante de su cuerpo.

\section{Reflexiones finales}

Preservar la asimetría entre niños y adultos constituye una condición innegociable para que un sujeto pueda emerger desde la palabra, gestionando su propio lugar de enunciación, operación posibilitada cuando el adulto, encarnando al Otro del lenguaje, lo aloja en el discurso y en un circuito de deseo.

En ese mismo sentido ubicamos que el reconocimiento del otro como semejante no se produce por generación espontánea, sino que constituye un proceso que muchas veces es facilitado desde el adulto, de quien se espera que regule ese lazo con el otro. Adulto, que, por otra parte, no necesariamente debe estar en posición de analista. De hecho, como señala Vasen (2000), en la práctica no hacemos sólo intervenciones analíticas, sino también señalamientos o intervenciones que simplemente tienen que ver con el reconocimiento y el respeto por un semejante. Es desde ese lugar asimétrico, desde el cual el adulto toma la palabra, donde esto puede ser enunciado de muchas maneras en el devenir cotidiano.

En efecto, Manuel ha podido ir constituyendo a esos otros como semejantes, a partir de la legalidad que se ha ido instalando, instituyendo, como marco simbólico referencial, que le ha permitido ir tejiendo lazos, contarse entre otros, desde su singularidad.

Precisamente hemos podido leer en estos registros que cuando la asimetría se sostiene, se introduce un marco de legalidad desde el discurso donde el niño puede empezar a jugar, echando mano al "como si”, que constituye el nudo de lo lúdico, y que le ofrece, por el efecto que produce de transformación de la realidad, la posibilidad de atemperar la consistencia del Otro (Marrone, 2005).

En esa misma dirección, pudimos observar que el adulto es también quien ofrece condiciones para el despliegue de la fantasía, la cual oficia de velamiento ante lo que deja su impronta desde lo real, vivido muchas veces como una amenaza para el sujeto. $\mathrm{Y}$ así también se crean condiciones para la elaboración de situaciones traumáticas a partir del discurso simbólico.

Por otro lado, la participación de $\mathrm{Ma}$ nuel durante dos años ininterrumpidos en el espacio nos llevó a ubicar la importancia de crear y ofrecer estabilidad en la infancia. Winnicott (2009), así como otros autores que se han dedicado al trabajo e investigación de los primeros tiempos constitutivos del niño, hacía mucho hincapié en esto como base para la organización interna y para construir confianza y seguridad en sí mismo y en el ambiente que rodea al niño. Esa estabilidad está constituida por esos pequeños momentos cotidianos donde el bebé y el niño se sienten sostenidos, soportados (función de holding) por otro u otros que participan de su crianza. Incluso él destaca que lo que hace valioso a un hogar o albergue, con relación a las experiencias con niños deprivados durante la guerra, "es su 
naturaleza permanente y no la eficacia con que está organizado” (2009, p.88). Este autor utiliza la cálida expresión "experiencias hogareñas primarias satisfactorias" (2009, p.75) para referirse a aquellas vivenciadas en un ambiente que se ajusta a las necesidades del niño pequeño, sienta las bases de la salud mental y cuenta con alguien que pueda alojarlo, sostenerlo. Estas experiencias, como tales, son irrecuperables, en caso de no haber tenido lugar en los primeros tiempos de constitución. Sin embargo, es posible que el niño pueda ir construyendo otras que reparen esa ausencia.

Muchas veces, en las zonas más vulnerables de la ciudad, nos encontramos con chicos que buscan, o que simplemente encuentran, ese soporte, esas "experiencias hogareñas primarias satisfactorias" en dispositivos grupales públicos y en las personas que los coordinan. Sería oportuno pensar, entonces, en los efectos subjetivos que tiene para tantos chicos, la inestabilidad de estos espacios grupales en instituciones públicas, dado que un lugar más en sus vidas se desintegra, se desarma y los deja otra vez sin ese alojamiento. Esa inestabilidad se produce muchas veces por el recambio de trabajadores que circulan de un área a otro o porque los espacios se cierran, se interrumpen, en general, producto de los cambios de gestión que no tienen en cuenta estos efectos. Aquí radica la diferencia, como señala Frigerio (2008), entre "trabajar con los niños y/o sobre los 'menores" (p.69), lo cual depara intervenciones totalmente diferentes.

Finalizando, podemos decir que el marco grupal le permitió a Manuel ir constituyendo recursos simbólicos propios en el lazo con los otros. Lo que un niño espera de un adulto es que se diferencie de él en tanto tal, para que él pueda ser niño, que la distancia genealógica se sostenga y, desde allí, el adulto pueda sostenerlo a él.

\section{Referencias}

- Amigo, S. (2005). Clínica de los fracasos del fantasma, Rosario: Homo Sapiens.

- Bleichmar, S. (2010). Psicoanálisis extramuros. Puesta a prueba frente a lo traumático, Buenos Aires: Entreideas.

- Bugacoff, A. (2000). Criminalidad e infancia, en AAVV, Superyó y filiación: Destinos de la transmisión, Rosario: Laborde.

- Duschatzky, S. y Corea, C. (2009). Chicos en banda: los caminos de la subjetividad en el declive de las instituciones. Buenos Aires: Paidós.

- Freud, S. (1997a). Psicología de las masas y análisis del yo, en Obras completas, tomo 19. Barcelona: Losada.

- Freud, S. (1997b). Varios tipos de carácter descubiertos en la labor analítica, en Obras completas, tomo 18. Barcelona: Losada.

- Frigerio, G. (2008). La división de las infancias: Ensayo sobre la enigmática pulsión antiarcóntica. Buenos Aires: Del estante.

- Kreszes, D. (2000). El lazo filiatorio y sus paradojas, en AAVV, Superyó y filiación: Destinos de la transmisión. Rosario: Laborde.

- Marrone, C. (2005). Eljuego, una deuda del psicoanálisis. Buenos Aires: Lazos.

- Minnicelli, M. (2013). Ceremonias minimas. Rosario: Homo Sapiens.

- Minnicelli, M. (2010). Infancias en estado de excepción: derechos del niño y psicoanálisis. 
Buenos Aires: Noveduc.

- Minnicelli, M. (2008). Escrituras de la ley en la trama social. Ensayo sobre la relación entre dispositivos, ceremonias mínimas y prácticas profesionales, en Revista Pilquen, Sección Psicopedagogía, Año X, $\mathrm{N}^{\circ} 5$.

- Minnicelli, M. (2004). De límites, confines y fronteras. Notas sobre el problema de los límites, de la autoridad y la responsabilidad, en Intersecciones entre clínica y escuela. Buenos Aires: Novedades edu- cativas.

- Rodulfo, R. (2001). El niño y el significante. Un estudio sobre las funciones del jugar en la constitución temprana. Buenos Aires: Paidós.

- Vasen, J. (2000). ¿Post-mocositos? Presencias, fantasmas y duendes en la clínica con niños y jóvenes de hoy. Buenos Aires: Lugar.

- Winnicott, D. W. (2009). Deprivación y delincuencia. Buenos Aires: Paidós.

- Winnicott, D. W. (2008). Realidad y juego. Barcelona: Gedisa. 